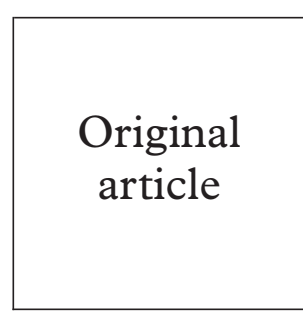

\title{
Psychological consequences of sexual assault among female attenders at a genitourinary medicine clinic
}

\author{
M Matthews, J Meaden, J Petrak, L Shepstone, J Evans
}

Department of
GU Medicine (Grove
Road Clinic), Norfolk
and Norwich Hospital
Health Care, NHS
Trust, Norwich,
Norfolk NR1 3SR
and Norfolk Mental
Health Care NHS
Trust, Hellesdan
Hospital, Norfolk,
Norfolk
M Matthews
J Meaden
J Petrak
L Shepstone
J Evans
Correspondence to:
Mime Matthews
Accepted for publication
5 November 1999

\section{Introduction}

Recent studies have reported $28-35 \%$ of UK genitourinary medicine (GUM) clinic attenders have been sexually assaulted. ${ }^{12}$ Research in the United Kingdom on other populations has indicated psychological problems may follow sexual assault among some survivors. ${ }^{3}$ The American literature suggests the psychological consequences of assault can be construed as post-traumatic stress disorder (PTSD). Intrusive thoughts, "flashbacks" and images of the assault, anxiety, and avoidance behaviour have been reported after assault both short and long term. Depressive symptoms have been reported after assault though it is unclear whether these are limited to the short term, or are longer lived. Factors influencing recovery from assault may include a history of previous assault, relationship to the assailant, and age at assault. Social support has been associated with good recovery from PTSD following a range of traumas though its relevance to sexual assault is not established.

The present study was conducted (a) to establish the prevalence of sexual assault in women attending a GUM clinic in a provincial setting in the United Kingdom and (b) to identify factors associated with psychological difficulties among female GUM clinic attenders who had been sexually assaulted.

\section{Subjects and methods}

The study was cross sectional in design and used an anonymous self report questionnaire developed by the researchers. Data were collected between October 1996 and April 1997. A sample of female attenders at the local GUM clinic was asked to complete the questionnaire after the medical consultation. The sample consisted of every fourth female attender at the clinics of the doctors involved in the study. The participants placed the completed questionnaires in a box provided. If a

Table 1 Psychological items with response rates (\%)

\begin{tabular}{llll}
\hline Question & No & A little & A lot \\
\hline Have you felt sadder and/or more depressed because of the assault? & 41.1 & 33.9 & 25.0 \\
Have you felt more anxious and fearful because of the assault? & 39.6 & 28.8 & 30.7 \\
Have images or thoughts of the assault come into your mind while & 37.9 & 34.5 & 27.6 \\
$\quad$ you are awake or dreaming? & & & \\
Have you avoided places or things that remind you of the assault? & 35.1 & 15.8 & 49.1 \\
Have you used more alcohol or drugs because of the assault? & 71.4 & 10.7 & 17.9 \\
Have you any sexual problems because of the assault? & 40.0 & 40.0 & 20.0 \\
Has your working life been affected badly? & 85.7 & 10.7 & 3.6 \\
Has your social/leisure life been affected badly? & 52.6 & 36.8 & 10.5 \\
Has your family life been affected badly? & 50.0 & 25.0 & 25.0 \\
Overall, do you feel distressed about the assault? & 18.3 & 58.3 & 23.3 \\
\hline
\end{tabular}

patient decided not to participate, a staff member placed a blank questionnaire in the box to indicate a non-participant. Informed consent was obtained and participation was voluntary. Full psychological support and treatment were available to all individuals disclosing a history of sexual assault whether or not they went on to participate in the study. Local ethics committee approval was obtained.

The questionnaire contained three sections. The first had items requesting information on age and whether or not sexual assault had ever occurred. In the questionnaire sexual assault was defined as "sexual activity against your will." For those women who indicated assault had occurred, further questions were asked about whether more than one assault had occurred, time since the last assault, if penetration of "mouth, vagina, or bottom" had occurred and the relationship between patient and assailant. The second section was composed of 10 items asking about various psychological consequences of the sexual assault experienced in the week before completion of the questionnaire. For each item, a score of 0 , 1 , or 2 was allocated for a response of "no," "a little," or "a lot of effect" respectively (table 1). The last section sought information about the agencies and social support obtained by the patient after the assault and how helpful they had found them.

The agencies rated were family, lover/ partner/husband, friends, general practitioner, police surgeon, police, accident and emergency department, "this clinic" (GUM, Norwich), rape crisis, victim support scheme, and others.

A statistical analysis was performed in order to identify any possible predictors of long term psychological effect following sexual assault.

Two outcome measures were used. These were both constructed from the 10 item questionnaire used in the study. The first of these outcomes is a binary variable recording whether there is or is not any evidence of psychological difficulties. This variable is positive for an individual if the response "a lot" was given for any of the 10 items on the questionnaire. The second outcome is a continuous psychological score with a range of $0-2$ and it is the average response score of the 10 items (or less than 10 if some were omitted).

Nine variables were considered as possible predictors. These were the age of the individual, the time (in months) since the assault, the age at assault, whether the individual was above or below the age of consent at time of assault, the 
assailant type, number of times assaulted, whether or not the assault included penetration, number of people told about the assault, the "best help score" (defined as the lowest of the help scores with a score of 5 indicating "very unhelpful" and 1 indicating "very helpful").

STATISTICAL ANALYSIS

A difference in median values of the continuous explanatory variables between those individuals with a long term psychological effect and those without was tested using a Wilcoxon two sample test. An association between long term effect and the categorical explanatory variables was tested for using a $\chi^{2}$ test.

The relation between the psychological score and the continuous explanatory variables was assessed using Spearman's rank correlation. A Wilcoxon two sample test was used to test for a difference in median psychological score between categories of the categorical variables. A Kruskal-Wallis test was used when there were more than two categories.

Statistical significance was set at the $5 \%$ level.

\section{Results}

A total of 279 questionnaires were distributed. Eleven questionnaires were not completed because of client refusal to participate or missing data. Sixty of $268(22.4 \%)$ respondents indicated they had been sexually assaulted; $78 \%(47 / 60)$ of the assaults had been penetrative and $37 \%(22 / 60)$ of the women had been assaulted on more than one occasion. The women varied in the time that had lapsed since assault (1 month to 36 years) with a median of 10 years since assault.

Data were not available for all 60 individuals for all explanatory variables, in particular, the age at assault was unavailable for 16 individuals.

The only significant relation between the presence of psychological difficulties and any of the explanatory variables was that with the number of people who were told about the assault $\left(\chi^{2}=6.27, \mathrm{p}=0.012\right)$. Those individuals who told two or more people were more likely to be experiencing psychological difficulties than those that told only one or no one. This explanatory variable was also significantly related to the psychological score. Those individuals who told two or more people about the assault had significantly worse psychological scores $(z=2.59, p=0.010)$.

There were also two explanatory variables with a near statistically significant relation to psychological score. Those individuals who were assaulted more than once had higher median scores than those assaulted only once $(z=1.89$, $\mathrm{p}=0.059)$ and those individuals who were above the age of consent also had higher median scores than those below $(z=1.92, p=0.06)$.

\section{Discussion}

This study of female GUM attenders found $22.4 \%$ of the women reported having been sexually assaulted; $78 \%$ of these assaults had been penetrative and $37 \%$ of the women had been assaulted on more than one occasion. The prevalence and severity of sexual assaults among this population appears high but is similar to other recent findings reported in UK GUM clinics. ${ }^{12}$ Rates for assault involving penetration in the present study are higher than found in Leicester $(57.8 \%)^{2}$ but lower than those identified in a London study $(87.7 \%) .{ }^{1}$

Women in the present study varied considerably in the time which had passed since the assault. A significant number of women continued to experience distress which they attributed to the assault (38/60 women fulfilled the study criteria for psychological effect). A longitudinal study in the United States indicated residual effects for a proportion of women (26\%) 4-6 years after rape. ${ }^{4}$ This is supported by a recent report that some women may access psychological services in a GUM setting many years after rape. ${ }^{5}$

The study identified one variable which was significantly related to psychological difficulties. Women reporting more psychological problems at the time of completing the questionnaire had sought more social support at the time of the assault. It is not clear whether women who sought more help were in an initially more distressed group who maintained higher symptom levels or whether some shortcomings in the support offered had led these women to seek more support. The quality of support rating used in the present study did not allow clarification of these alternative explanations. Future research is needed into the characteristics of social support that might be associated with recovery after the assault.

Clinically, the present study suggests a significant number of women attending the GUM clinics in provincial as well as urban settings may have been sexually assaulted and may continue to experience psychological difficulties. Variables which may be associated with such difficulties include age at assault and a history of previous assault. Controlled trials have confirmed the impact of cognitive therapy on PTSD following rape at 6 months $^{6}$ and 10 months of follow up. ${ }^{7}$ Clinical psychologists working within GUM clinics are well placed to assess and treat those with psychological difficulties after sexual assault.

We thank Grove Road clinic staff for advice and support and Rebecca Kirk for advice and typing the manuscript. Contributors: $M M$, clinical psychologist, was the main author
of the questionnaire and article; JM was the participating and of the questionnaire and article; JM was the participating and reviewing consultant physician; JP was the clinical psychologist and psychological supervisor; LS was the medical statistical supervisor, statistical adviser, and co-author of revised short report; JE was the co-author of questionnaire and article and participating consultant physician.

1 Petrak J, Skinner CJ, Claydon EJ. The prevalence of sexual assault in a genitourinary medicine clinic: service implications. Genitourin Med 1995;71:98-102.

2 Keane FEA, Young SM, Boyle HM. The prevalence of previous sexual assault among female attenders at a department of genitourinary medicine. Int $f$ STD AIDS 1996; $7: 480-4$

3 Bownes IT, O'Gorman EC, Sayers A. Assault characteristics and post traumatic stress disorder in rape victims. Acta Psychiatr Scand 1991;83:27-30.

4 Burgess A, Homstrom L. Rape trauma syndrome. Am f Psychiatry 1974;131:981-6.

5 Petrak J, Doyle A, Williams L, et al. The psychological impact of assault: a study of female attenders of a sexual health psychology service. Sex Marital Ther 1997;12:339-45.

6 Resick PA, Schicke MK. Cognitive processing therapy for Resick PA, Schicke MK. Cognitive processing therapy for
sexual assault victims. $\mathcal{F}$ Consult Clin Psychol 1992;60:74856.

7 Foa EB. Trauma and women: course, predictors and treatment $\mathcal{f}$ Clin Psychiatry 1997;58:25-8. 